\title{
New literacies and teacher learning: Professional development and the digital turn
}

\author{
Michele Knobel and Judy Kalman (Eds). Peter Lang, New York, etc., \\ 2016, 262 pp. New Literacies and Digital Epistemologies series, vol. 74. \\ ISBN 978-1-4331-2912-4 (hbk), ISBN 978-1-4331-2911-7 (pbk), ISBN \\ 978-1-4541-9193-3 (ePUB), ISBN 978-1-4539-1823-4 (ePDF)
}

\section{Ulrike Hanemann ${ }^{1}$ (D)}

Accepted: 25 March 2021 / Published online: 2 April 2021

(c) UNESCO Institute for Lifelong Learning and Springer Nature B.V. 2021

There is general agreement that teachers play a critical role in improving learning. For that reason, teacher learning through professional development has increasingly been one of the key concerns of educational authorities for some time. High hopes are now being placed on digital technologies to improve the quality of teaching and learning. Hence, in recent years the focus of attention to improve the effectiveness of professional development has moved towards the potential of digital technologies to enhance and enrich learning environments for teachers, too. However, when it comes to teachers' learning, the much-promoted learner-centred approach has still to be realised. Teachers are often seen as trainees rather than as learners themselves who benefit best from "teacher-centred" and practice-oriented professional development opportunities.

There is a growing body of research that points to coaching and collaborative and technology-based approaches as effective ways of supporting teachers' professional growth (e.g. Burns and Lawrie 2015; Gaible and Burns 2005; Kraft, Blazar and Hogan 2018; Ostrand, Seylar and Luke 2020). ${ }^{1}$ Moreover, in-service teacher training and professional development that has been able to positively influence

\footnotetext{
1 Burns, M., \& Lawrie, J. (Eds.) (2015). Where it's needed most: Quality professional development for all teachers. New York, NY: Inter-agency Network for Education in Emergencies. Retrieved 17 February 2021 from https://inee.org/system/files/resources/Where_Its_Needed_Most_-_Teacher_Professional_ Development_2015_LowRes.pdf.

Gaible, E., \& Burns, M. (2005). Using technology to train teachers: Appropriate uses of ICT for teacher professional development in developing countries. Washington, DC: infoDev/World Bank. Retrieved 22 December 2020 from http://www.infodev.org/en/Publication.13.html.

Kraft, M.A., Blazar, D., \& Hogan D. (2018). The effect of teacher coaching on instruction and achievement: A meta-analysis of the causal evidence. Review of Educational Research, 88(4), 547-588. https:// doi.org/10.3102/0034654318759268.
}

Ulrike Hanemann

hanemann.ulrike@gmx.de

1 Independent International Literacy and Education Specialist, Hamburg, Germany 
teachers' and students' learning is usually ongoing, tailored, focused and practical (e.g. Béteille and Evans 2019). ${ }^{2}$

The current COVID-19 pandemic has increased the level of attention being given to the use of digital means to ensure the continuation of learning. This has highlighted the urgent need to strengthen support to teachers and their professional development even more in order to close existing learning and digital divides. While teachers with little experience in integrating digital resources in their classroom activities see themselves thrown in at the deep end, teachers who successfully tackle this situation have shown readiness to take on their increasingly complex role of facilitators of learning with digital technology.

The contributions to New Literacies and Teacher Learning: Professional Development and the Digital Turn, edited by Michele Knobel and Judy Kalman, offer examples of how teachers have engaged in innovative ways to improve their students' learning outcomes. These examples refer to projects which used different approaches to teachers' professional development in a range of situations, grade levels, activities, scales and national contexts - including Argentina, Australia, Canada, Finland, Mexico, Norway and the United States, - and occurred in primary and secondary education, in adult literacy education and in university contexts.

A common thread across the book's eleven chapters is an interest in teachers taking up what the editors, who authored the introductory chapter, call "new literacies" in response to the "digital turn" (p. 5). This interest is essentially about digitally mediated literacy and learning practices that have been examined from a sociocultural (New Literacy Studies) orientation and are characterised by a new "ethos" (p. 6). This ethos recognises the complexity of teaching and its situatedness in classrooms, schools and communities, and favours ways of teacher learning that contribute to an enriching professional practice. It further involves a deep understanding of teaching as a social practice and of the potential of digital technologies to become part of meaningful and creative learning experiences for both teachers and their learners.

In their introductory Chapter 1, Knobel and Kalman provide an overview of teacher learning, digital technologies and new literacies. They start from a critical review of research on teachers' professional development. In their view, this research often pays too little attention to the complex systems within which teachers work, and puts too much emphasis on "quick fixes" (p. 4). They criticise that academic literature "has been dominated by 'education technology' accounts of "upskilling' teachers" (p. 4) with regard to using and learning about digital technologies in professional development. In opposition to this, the authors discuss the study

\footnotetext{
Footnote 1 (continued)

Ostrand, K.V., Seylar, J., \& Luke, C. (2020). Prevalence of coaching and approaches to supporting coaching in education. Wahsnington, DC: Digital Promise. Retrieved 22 December 2020 from http:// digitalpromise.org/wp-content/uploads/2020/01/Prevalence_of_Coaching_Report.pdf.

2 Béteille, T., \& Evans, D.K. (2019). Successful teachers, successful students: Recruiting and supporting the world's most crucial profession. World Bank Policy Approach to Teachers series. Washington, DC: World Bank. Retrieved 22 December 2020 from http://documents1.worldbank.org/curated/en/23583 1548858735497/Successful-Teachers-Successful-Students-Recruiting-and-Supporting-Society-s-MostCrucial-Profession.pdf.
} 
of "new literacies" as one alternative response to the "digital turn". This involves a better understanding of new - digitally mediated or produced - literacy practices as social practices, and how teachers can take these up in their classrooms technologically and in terms of a different "ethos". Digital technologies and digital practices are considered as being just one element of developing transformative teaching and learning approaches "that center-stage collaborative and social learning" (p. 8) as an open process.

Knobel and Kalman particularly emphasise the importance of social learning and a participatory culture present in the examples of professional learning or development that are showcased in the chapters of the book. While the various contributors' experiences refer to different aspects of using various digital resources, all chapter authors share the view that "digital stuff" is not of central concern. The focus of their discussions about using new digital practices in literacy and learning is on "the pedagogical orientations, collaborative and maker learning theories, the complexities of teachers' workplaces, among many other contributing factors" (p. 12).

In Chapter 2, Oscar Hernández Razo, Victor Rendón Cazales and Judy Kalman illustrate the experience of a professional development programme designed by the Mexican Laboratory for Education, Technology and Society (LETS) to explore how junior high school teachers in Mexico City might include technology in their practice. The centrepiece of their professional development proposal is the concept and practice of accompaniment that encourages teachers to reflect on their practice while learning to use digital technology in their teaching. The accompaniment approach is built on five interrelated aspects: continuity, collaboration, reflection, construction and working in the classroom. The lessons drawn from this experience include that the use of digital technology in innovative ways requires working with teachers to broaden their understanding of how digital technology can help transform their work with learners, and that professional development requires time to collectively explore, create and review activity designs for the classroom.

In Chapter 3, Susi Bostock, Kathleen Lisi-Neumann and Melissa Collucci describe the professional learning journey of two primary education teachers (Bostock and Lisi-Neumann) in the United States with the development of upcycled products (by means of YouTube and popular culture) and a reading programme. By embracing Thirdspace ${ }^{3}$ theory and pedagogy, they created an additional learning space between the classroom and home that welcomed experiences, practices, knowledge and skills of the students and their families. This required "a shift in thinking about where learning takes place, the roles of teachers and students and the cultural changes that promote and result from learning" (p. 61). For these two teachers, embracing "do-it-ourselves approaches" to professional learning has been a reciprocal process of learning from their students, while at the same time supporting their learning as it unfolded. They conclude that their Thirdspace classroom

\footnotetext{
3 They explain that their choice of spelling it like this " - one word, capital T -" is deliberate, because their "classroom work aligns closely with the sentiment ... that embracing this complicated theory in the practical world of the classroom means we work tirelessly towards creating metaphorical and actual "spaces" for learning that extend beyond typical classroom mandates and expectations" (p. 46).
} 
approach allowed for a professional growth that would not have been possible in a pre-packaged one-day training workshop.

The experience of innovative and collaborative learning within a whole-school project in Canada is presented by Heather Lotherington, Stephanie Fisher, Jennifer Jenson and Laura Mae Lindo in Chapter 4. A teacher-university action research project to develop pedagogies for multimodal literacy practices resulted in a model of professional development as a by-product. This model of in-house professional development involved revising the educational infrastructure and following the principles: "learn together, learn at home, remix the curriculum, build resilience to failure, play to learn, and be self-reliant" (p. 84). Drawing on multimodality theory, the authors share an inspiring example of an experimental multimedia class project conducted by a special education teacher.

In Chapter 5, Ola Erstad analyses several projects that focus on high school teachers' development of innovative projects with their students in Norway. He advocates for a closer relationship between in- and out-of-school activities, learning spaces and literacy practices. One example of the creation of such connected learning spaces is the collaboration of two student groups from different socio-economic backgrounds on the development of an online newspaper, one for each school, which reported on students, their school and their community from "the other side". Another example is about providing students with opportunities to cross the boundaries between formal and informal spaces of knowledge-building through digital storytelling. These examples serve to illustrate important aspects of a teacher professional development practised in Norwegian schools today "that is always in process and not tied to oneoff events where an expert comes in and tells teachers what to do" (p. 103).

In Chapter 6, drawing on the theoretical framework of multiliteracies, Reijo Kupiainen, Hanna Leinonen, Marita Mäkinen and Angela Wiseman discuss a multi-school professional development initiative in Finland that applied collaborative pedagogy in the attempt to strengthen multiliteracy competence through digital learning approaches in the classroom. Multiliteracy presents a new orientation in the current Finnish National Core Curriculum. In the featured Digital Book Project, which took place in six primary schools, teachers collaboratively designed a new learning environment across different learning subjects based on digital technologies (especially those available on iPads and tablets). The project was oriented by a technology integration framework called Technological, Pedagogical and Content Knowledge (TPACK), which stresses the need for teachers to understand how technological, pedagogical and content knowledge and contextual parameters interrelate. On the basis of this experience, the authors draw attention to the importance of "collective efficacy" (p. 125) in developing new school and pedagogical cultures, as opposed to "top-down, expert-driven professional development" (p. 127). They identify the Digital Book Project as an example of "professional capital in action" (p. 125): Teachers are supported by each other, principals and the eLearning Centre to create new learning environments and relationships - in short, a new pedagogy of multiliteracies.

Professional development in the context of a massive one-computer-per-child programme in Argentina (Conectar Igualdad) is the focus of Inés Dussel's research in Chapter 7. She critically examines the experiences of social science teachers (and 
their students) in four public secondary schools in the province of Buenos Aires. The goal of her study was to analyse the ways in which classroom interactions and rules for evaluating what counts as school knowledge were being transformed with or by the introduction of digital media. While the observed class activities involving multimodal production were rich in languages and in the critical thinking they demanded, "most remained in the realm of possibility and did not become concrete realizations" (p. 144). Though teachers opted for a horizontal pedagogy, they lacked awareness of opportunities for their students to reflect and achieve higher levels of "more productive and intellectually challenging work" (p. 146). In other words, the full potential of digital technologies remained largely invisible or unrealised. Dussel concludes that professional development will need to "seek ways to open up spaces for teachers' reflection on and creativity with how to deal more productively with the tensions that digital media bring to the classrooms" (p. 148).

In Chapter 8, Teresa Strong-Wilson, Claudia Mitchell and Marcea Ingersoll explore the application of multidirectional memory-work and the "phase space" as an alternative framework for teacher-led professional development in a digitalbased project with school and university educators in Canada. In taking a "digital retreat" approach, the authors organised a series of workshops with teachers to explore productive uses of digital technologies by working through memory in multidirectional ways. In the centre of this multi-stage process was the opportunity for professional growth through the sharing of digital drafts of the project artefacts in collegial spaces. Although the authors admit that their professional development initiative was not fully teacher-led, they see the potential for this work to become teacher-driven.

The book's only contribution on technology-based professional development in adult basic education is presented in Chapter 9 by Erik Jacobson who was involved in different projects in the United States that took an approach to professional development which focused on the agency of teachers as learners. He outlines three major issues that complicate technology-related professional development in adult basic education: a diverse student population, a diverse teacher population and limited resources. He further presents a pedagogical model that respects the agency of the learner and recognises the social basis of knowledge generation. Consequently, the three examples of professional development opportunities he then provides use approaches of self-directed learning, collaborative project-based learning, and facilitated exploration. All of them used digital technologies such as social networking resources or built a professional platform (the Adult Literacy Education Wiki). The author concludes with the recommendation to prioritise (a) building on the progressive heritage of adult basic education; (b) expanding the notions of professional development; and (c) problem-posing in technology-rich environments in future professional development around technology within adult basic education.

In Chapter 10, Carly Biddolph and Jen Scott Curwood examine the intersection of Twitter and professional learning. Their study draws on data from an online survey, in-depth interviews and tweets of English teachers, mainly from an Australian context, to analyse how the popular social media platform Twitter.com is used as a professional development space. Key factors that influenced teachers' use of Twitter were agency in how, what and why teachers engage in professional 
learning, accessibility in terms of funding and location, and reciprocity in how learning occurs and is socially validated. The findings further indicate that Twitter, as an online community of practice, embodies the characteristics of effective professional learning because it is self-directed. Consequently, the authors advocate for the inclusion of Twitter "as a powerful complement to recognised and certified professional development" (p. 215).

Finally, in Chapter 11, Christina Cantrill and Kylie Peppler illustrate an example of professional development that is based on the "Connected Learning" approach and supports production-centred and interest-driven learning in openly networked teaching communities in the context of the US-based National Writing Project. The Connected Learning approach seeks to engage the interests, social capital and future opportunities of students by linking learning across classroom, school, home and community. The assumption underpinning the design of Connected Learning classrooms is "that the more teachers fluidly connect students to the outside world, the more relevant and impactful they make the learning experience" (p. 221). This required the creation of a new ecosystem for learning which included productioncentred professional development. The authors describe the experience of professional development workshops with practitioners from the National Writing Project who wrote a short story and created an e-puppet representing one of the characters to experiment, in playful ways, with a process of "'messy' learning, which allows for multiple points of entry and divergent goals" (p. 234). This face-to-face openly networked learning was complemented by online activities (e.g. blogs, forums, e-courses, etc.). Learning alongside each other as connected teachers and "makers in teaching" through such activities is perceived by the authors as the creation of "shared ecosystems for learning" and key parts of "a larger movement to rethink learning in a digital age" (p. 238).

All the contributions compiled in this book illustrate how different initiatives have approached professional development with a clear emphasis on "professional practice and teacher learning as something that's complex, highly situated, deeply collaborative and participatory, and that takes into consideration the thoroughly social nature of 'being a teacher"' (p. 4). The experiences shared in this collection demonstrate that meaningful use of digital technologies in transformative processes of teaching and learning require time, committed engagement, critical reflection and multiple opportunities to learn from and with others. This confirms findings from earlier research that teacher learning and professional development initiatives are successful when implemented in everyday practice at one's own institution and in cooperation with colleagues. While in many contexts, particularly within the current pandemic, professional development increasingly needs to take place in digital environments, learning how to use and integrate digital technologies in classroom activities cannot become the dominant and sole dimension of empowering and transformative teacher learning. The contributions in this book testify to how this can be avoided, and even more, how these new technologies can be creatively taken up and meaningfully used in literacy and learning practices across different learning spaces.

This book is of interest for all those who are engaged in pre-service or in-service teacher education in the broadest sense, including academics, researchers, students, teachers, educators and practitioners. It is likely to inspire particularly those readers 
who feel the need to make some profound changes in existing approaches to teacher learning and professional development. However, most of the experiences are based on projects which are implemented in partnership with universities and research institutions with the aim to explore the educational potential of new technologies. This raises questions about their suitability for daily use and mainstream teacher education.

Moreover, in the Nordic countries, teachers are considered as self-sufficient professionals who are expected to organise their teaching independently and adopt new pedagogical strategies autonomously, a situation that differs from that of the majority of countries in the rest of the world. This raises additional questions about the transferability of the presented experiences to other contexts. In her commendable critical analysis of the massive technology-intensive Conectar Igualdad (Connect Equality) project in Argentina, for example, Dussel shows that even in rather favourable learning environments teachers' limited understanding of the pedagogical potential of new technologies, multimodal classroom strategies and their new role can be in the way of the expected transformations. It would be desirable to see a follow-up collection soon of how such inspiring and thought-provoking experiences have achieved making their way into mainstream in-service teacher learning and professional development in different contexts.

Publisher's Note Springer Nature remains neutral with regard to jurisdictional claims in published maps and institutional affiliations. 